University of Nebraska - Lincoln

DigitalCommons@University of Nebraska - Lincoln

Faculty Publications: Department of Entomology

$4-2020$

\title{
Effect of Temperature on Plant Resistance to Arthropod Pests
}

\author{
James R. Nechols \\ Kansas State University, jnechols@ksu.edu \\ Ashley R. Hough \\ Kansas State University \\ David C. Margolies \\ Kansas State University, dmargoli@ksu.edu \\ John R. Ruberson \\ University of Nebraska-Lincoln, jruberson2@unl.edu \\ Brian P. McCornack \\ Kansas State University, mccornac@ksu.edu
}

See next page for additional authors

Follow this and additional works at: https://digitalcommons.unl.edu/entomologyfacpub

Part of the Entomology Commons

Nechols, James R.; Hough, Ashley R.; Margolies, David C.; Ruberson, John R.; McCornack, Brian P.; Sandercock, Brett K.; and Murray, Leigh, "Effect of Temperature on Plant Resistance to Arthropod Pests" (2020). Faculty Publications: Department of Entomology. 853.

https://digitalcommons.unl.edu/entomologyfacpub/853

This Article is brought to you for free and open access by the Entomology, Department of at DigitalCommons@University of Nebraska - Lincoln. It has been accepted for inclusion in Faculty Publications: Department of Entomology by an authorized administrator of DigitalCommons@University of Nebraska - Lincoln. 


\section{Authors}

James R. Nechols, Ashley R. Hough, David C. Margolies, John R. Ruberson, Brian P. McCornack, Brett K. Sandercock, and Leigh Murray 


\title{
Effect of Temperature on Plant Resistance to Arthropod Pests
}

\author{
James R. Nechols, ${ }^{1}$ Ashley R. Hough, ${ }^{1}$ \\ David C. Margolies, ${ }^{1}$ John R. Ruberson, ${ }^{2}$ \\ Brian P. McCornack, ${ }^{1}$ Brett K. Sandercock, ${ }^{3}$ \\ and Leigh Murray ${ }^{4}$ \\ 1 Department of Entomology, Kansas State University, \\ 1603 Old Claflin Place, Manhattan, KS 66506 \\ 2 Department of Entomology, University of Nebraska, \\ 103 Entomology Hall, Lincoln, NE 68583 \\ 3 Department of Terrestrial Ecology, Norwegian Institute for Nature Research, \\ P.O. Box 5685 Torgarden, 7485 Trondheim, Norway \\ 4 Department of Statistics, Kansas State University, 101 Dickens Hall, \\ 1116 Mid-Campus Drive North, Manhattan, KS 66506 \\ Corresponding author - J. R. Nechols, email jnechols@ksu.edu
}

\begin{abstract}
Temperature has a strong influence on the development, survival, and fecundity of herbivorous arthropods, and it plays a key role in regulating the growth and development of their host plants. In addition, temperature affects the production of plant secondary chemicals as well as structural characteristics used for defense against herbivores. Thus, temperature has potentially important implications for host plant resistance. Because temperature directly impacts arthropod pests, both positively and negatively, distinguishing direct effects from indirect effects mediated through host plants poses a challenge for researchers and practitioners. A more comprehensive understanding of
\end{abstract}

Published in Environmental Entomology 49:3 (2020), pp 537-545

doi: $10.1093 /$ ee/nvaa033

Copyright (C) 2020 by the authors. Published by Oxford University Press on behalf of

Entomological Society of America. Used by permission.

Submitted 6 December 2019; accepted 16 March 2020; published 13 April 2020. 
how temperature affects plant resistance specifically, and arthropod pests in general, would lead to better predictions of pest populations, and more effective use of plant resistance as a management tactic. Therefore, the goals of this paper are to 1) review and update knowledge about temperature effects on plant resistance, 2) evaluate alternative experimental approaches for separating direct from plant-mediated indirect effects of temperature on pests, including benefits and limitations of each approach, and 3) offer recommendations for future research.

Keywords: host plant resistance, insect-plant interactions, plant-mediated effects, temperature-induced effects

Temperature is an important environmental driver in the evolutionary ecology of plants and animals, and it plays a key role in shaping the life histories of poikilothermic organisms (Precht et al. 1973a). Temperature affects poikilotherms directly by setting upper and lower limits for development and survival, and by regulating population growth through temperature-dependent processes. It also mediates plant-arthropod interactions via direct effects on plants (Vegis 1973) and arthropods (Precht et al. 1973b), and indirectly by influencing host plant quality (Pisek et al. 1973, Basra 2001). Temperature-induced changes in plant quality that impact insect herbivores include phytochemicals produced for defense by plants, availability of nutrients such as sugars and amino acids, and undigestible or impenetrable plant structures (Went 1953, Denno and McClure 1983, Ishaaya 1986, Zhu-Salzman et al. 2008, Shuman and Baldwin 2016).

Host plant resistance is a pest management tactic that exploits natural plant defenses, traditionally, through breeding programs designed to augment traits that confer resistance to pests (Painter 1951, Beck 1965, Smith 2006). Plants defend themselves by three mechanisms: 1) antixenosis (nonpreference) - physical and/or chemical traits that cause pests to avoid plants, 2) antibiosis - plant characteristics that negatively affect pest fitness, and 3) tolerance-adaptations that allow plants to withstand or compensate for tissue damage or loss that would be deleterious to susceptible plants (Painter 1951). Resistance may be present throughout a plant's life cycle (constitutive resistance), or it may be elicited in response to environmental stimuli such as feeding by insects (induced resistance) (Koch et al. 2016).

An accumulating body of evidence indicates that a change in temperature elicits changes in plants that alter the expression of resistance to 
insect pests. In some cases temperature enhances resistance (Sosa 1979, Thindwa and Teetes 1994, Chen et al. 2014, Hough 2016, Hough et al. 2017); in others it weakens it (Cartwright et al. 1946, Hackerott and Harvey 1959, McMurtry 1962, Isaak et al. 1963, Kindler and Staples 1970, Wood and Starks 1972, Johnson et al. 1980, Salim and Saxena 1991, Walters et al. 1991, Harvey et al. 1994, Richardson 2011, Chen et al. 2014, Chirumamilla et al. 2014). And in a few cases, temperature appears to have no effect on plant resistance (Dahms and Painter 1940, Jackai and Inang 1992, Randolph et al. 2008).

Altered fitness or population growth in an herbivorous insect pest may be related to a temperature-induced change in the expression of plant resistance. However, a change in fitness or population growth can also result from direct temperature effects. Distinguishing direct from indirect temperature effects can be difficult, but it is essential for making accurate predictions of pest populations and associated crop damage. To adequately understand the role of temperature in the expression of plant resistance, more research is needed to characterize and quantify plant and pest responses under different temperatures, including the thermally variable conditions that occur in the field. Therefore, our paper has three aims: to 1) expand and update knowledge about temperature effects on plant resistance and associated pest responses, 2) compare different experimental approaches for elucidating temperature effects on plant resistance, including ways to distinguish them from direct effects on arthropod pests, and 3) identify knowledge gaps and make recommendations for future research.

\section{Temperature Effects on Plant Resistance}

Currently, 26 experimental studies have investigated temperature to determine if it influences the expression of plant resistance to insect pests (Table 1). Of these, 21 studies, representing eight pest species- most of them aphids-in three insect orders and four families, provide evidence that temperature modifies the level of plant resistance. In five other studies, temperature either did not appear to influence plant resistance (Dahms and Painter 1940, Randolph et al. 2008), or the findings were inconclusive because it was not possible to distinguish direct effects of temperature on pests from indirect effects on plant resistance 
Table 1. Insect taxa for which temperature-induced changes in host plant resistance have been investigated

\begin{tabular}{|c|c|c|c|}
\hline Order & Family & Species & Source \\
\hline \multirow[t]{25}{*}{ Hemiptera } & \multirow[t]{19}{*}{ Aphididae } & Schizaphis graminum Rondani & Wood and Starks (1972) \\
\hline & & \multirow[t]{3}{*}{ Greenbug } & Schweissing and Wilde (1979) \\
\hline & & & Harvey et al. (1994) \\
\hline & & & Thindwa and Teetes (1994) \\
\hline & & Aphis glycines Matsumura & Richardson (2011) \\
\hline & & \multirow[t]{3}{*}{ Soybean aphid } & Chirumamilla et al. (2014) \\
\hline & & & Hough (2016) \\
\hline & & & Hough et al. (2017) \\
\hline & & Therioaphis maculata (Buckton) & Hackerott and Harvey (1959) \\
\hline & & \multirow[t]{4}{*}{ Spotted alfalfa aphid } & McMurtry (1962) \\
\hline & & & Isaak et al. (1963) \\
\hline & & & Schalk et al. (1969) \\
\hline & & & Kindler and Staples (1970) \\
\hline & & Acyrthosiphon pisum (Harris) & Dahms and Painter $(1940)^{a}$ \\
\hline & & Pea aphid & Isaak et al. (1963) \\
\hline & & Aulacorthum solani (Kaltenbach) & \multirow[t]{2}{*}{ Walters et al. (1991) } \\
\hline & & Foxglove aphid & \\
\hline & & Diuraphis noxia Mordvilko & \multirow[t]{2}{*}{ Randolph et al. (2008) ${ }^{a}$} \\
\hline & & Russian wheat aphid & \\
\hline & \multirow[t]{2}{*}{ Cicadellidae } & Empoasca fabae (Harris) & \multirow[t]{2}{*}{ Casteel et al. (2006) ${ }^{a}$} \\
\hline & & Potato Leafhopper & \\
\hline & \multirow[t]{2}{*}{ Delphacidae } & Sogatella furcifera (Horváth) & \multirow[t]{2}{*}{ Salim and Saxena (1991) } \\
\hline & & Whitebacked planthopper & \\
\hline & \multirow[t]{2}{*}{ Coreidae } & Clavigralla tomentosicollis (Stål) & \multirow[t]{2}{*}{ Jackai and Inang $1992^{a}$} \\
\hline & & Brown cowpea coreid bug & \\
\hline Coleoptera & Curculionidae & Hypera postica Gyllenhal & Johnson et al. (1980) \\
\hline & & Alfalfa weevil & \\
\hline \multirow[t]{5}{*}{ Diptera } & \multirow[t]{5}{*}{ Cecidomyiidae } & Mayetiola destructor (Say) & Cartwright et al. (1946) \\
\hline & & \multirow[t]{4}{*}{ Hessian fly } & Sosa and Foster (1976) \\
\hline & & & Sosa $(1979)^{a}$ \\
\hline & & & Tyler and Hatchett (1983) \\
\hline & & & Chen et al. (2014) \\
\hline \multirow[t]{2}{*}{ Lepidoptera } & \multirow[t]{2}{*}{ Pyralidae } & Maruca testulalis Geyer & \multirow[t]{2}{*}{ Jackai and Inang $(1992)^{a}$} \\
\hline & & Legume pod borer & \\
\hline
\end{tabular}

a. Data inconclusive or do not provide evidence of temperature effect. 
(Sosa 1979, Jackai and Inang 1992) or the number of temperature treatments was too low to determine whether plant resistance was changing in response to temperature (Casteel et al. 2006).

Dahms and Painter (1940), who worked with the pea aphid, Acyrthosiphon pisum (Harris) (Hemiptera: Aphididae), were the first to suggest that a change in temperature may alter the expression of plant resistance. Four decades later, Tingey and Singh (1980) reviewed the literature on temperature-induced plant resistance, citing several studies in which a decrease in the expression of resistance occurred under high and low temperatures. Their review also documented the effects of fluctuating temperature and plant exposure time on resistance. Absent from their review were examples where a change in temperature caused an increase in resistance. Our paper reviews the literature published before and after 1980. We also discuss topics pertaining to temperature effects on plant resistance not covered in Tingey and Singh's review.

Based on the current literature, there is considerable variation in the way that temperature influences the expression of plant resistance, and which pest traits are affected. Resistance may strengthen or weaken as temperature increases or decreases, and sometimes both high and low temperatures will have the same effect. Temperature-induced changes in resistance appear to be malleable in that a change in resistance can be reversed by reversing the direction of the temperature change to which plants are exposed. The following sections illustrate the diversity and complexity of plant responses to temperature that have been documented to date.

\section{Changes in Plant Resistance in Response to Temperature}

Throughout, we refer to the terms 'high' and 'low' to indicate temperatures that cause an increase or a decrease in the expression of plant resistance. We acknowledge that these are relative terms depending on the range of temperatures tested, and what represents a 'high' and 'low' temperature for a given crop plant or pest. Changes in resistance typically occur at higher or lower temperatures where the differences in responses between resistant and susceptible plants either increase or decrease relative to some middle range of temperatures where differences in responses between resistant and susceptible plants are consistent and at an intermediate level. 
Enhanced resistance at high temperatures.

In the greenbug, Schizaphis graminum (Rondani) (Hemiptera: Aphididae), biotypes evolve to overcome resistance to specific lines of small grain crops. In two studies, an increase in the expression of resistance was observed in greenbug biotypes when temperature was increased. Thindwa and Teetes (1994) showed that population growth and fecundity of biotypes $\mathrm{C}$ and $\mathrm{E}$ were lower, and development time longer, on antibiotic resistant sorghum (Sorghum bicolor (L.) Moench [Poales: Poaceae]) lines compared to susceptible lines at $30^{\circ} \mathrm{C}$, but not at 26 or $21^{\circ} \mathrm{C}$. Thindwa and Teetes also showed that tolerant sorghum lines had less damage, and fewer greenbugs recruited to antixenotic lines, at $30^{\circ} \mathrm{C} \mathrm{com-}$ pared to lower temperatures.

In the soybean aphid, Aphis glycines Matsumura (Hemiptera: Aphididae), Hough et al. (2017) reported consistently lower survival on a resistant soybean (Glycine max (L.) Merrill [Fabales: Fabaceae]) line compared to a susceptible line at temperatures that ranged from 15 to $30^{\circ} \mathrm{C}$. However, whereas aphid survival was equally high at 25 and $30^{\circ} \mathrm{C}$ on susceptible soybeans, on resistant plants there was a sharp decrease in survival between 25 and $30^{\circ} \mathrm{C}$. The authors concluded that high temperatures induce a high level of resistance to this pest.

\section{Enhanced resistance at low temperatures.}

Studies with the Hessian fly, Mayetiola destructor (Say) (Diptera: Cecidomyiidae), offer evidence that low temperatures may maintain or enhance plant resistance. Sosa (1979) conducted an experiment in which he made reciprocal transfers of resistant wheat (Triticum aestivum L. [Poales: Poaceae]) plants that contained newly hatched Hessian fly larvae from 27 to $18^{\circ} \mathrm{C}$ and from 18 to $27^{\circ} \mathrm{C}$. The transfers were made from 1 to $7 \mathrm{~d}$ after exposure to the initial temperature. Results showed that the longer that infested plants were kept at $18^{\circ} \mathrm{C}$, the lower the larval survival rate and the percentage of infested plants. Conversely, longer exposure to the higher temperature resulted in higher Hessian fly survival and less plant damage. From these findings Sosa concluded that low temperatures maintained or enhanced resistance, whereas high temperatures decreased or prevented the expression of resistance. However, because the experiment did not include a susceptible plant as a control, and larvae were on plants when transfers were made between temperatures, the results are inconclusive with respect to a temperature-induced 
change in resistance. Specifically, the findings do not eliminate the possibility that temperature had a direct adverse effect on larval survival. However, this is unlikely because a later study by Chen et al. (2014) showed high larval survival on both susceptible and resistant wheat cultivars that were transferred at different intervals from $14-16^{\circ} \mathrm{C}$ to $20^{\circ} \mathrm{C}$. Consistent with Sosa's results, Chen et al. found high larval survival only on plants that had been maintained at higher temperatures. Therefore, resistance to Hessian flies only appears to be expressed at lower temperatures.

In a study with the soybean aphid, Hough (2016) found that both survival and progeny production were lower on resistant soybean seedlings that had been conditioned at $20^{\circ} \mathrm{C}$ before infestation and transfer to $25^{\circ} \mathrm{C}$ compared to seedlings that were conditioned at $30^{\circ} \mathrm{C}$.

\section{Reduced resistance at high temperatures.}

Four studies of different Hessian fly biotypes confirm that resistance, based on larval survival and/or plant infestation, is not expressed at higher temperatures (Cartwright et al. 1946, Sosa and Foster 1976, Tyler and Hatchett 1983, Chen et al. 2014). In two studies, the expression of resistance was progressively weaker at temperatures above 20$22^{\circ} \mathrm{C}$, and it appeared to be lost at $27^{\circ} \mathrm{C}$ (Sosa and Foster 1976 , Chen et al. 2014).

In a study of the alfalfa weevil, Hypera postica Gyllenhal (Coleoptera: Curculionidae), Johnson et al. (1980) compared developmental times at temperatures ranging from 17 to $28^{\circ} \mathrm{C}$ on resistant and susceptible alfalfa (Medicago) species (Fabales: Fabaceae) which varied in glandular trichome density. Differences in weevil development time between resistant and susceptible plants became progressively smaller as temperature increased, suggesting that resistance was weaker at higher temperatures. Consistent with these findings, Walters et al. (1991) found similar rates of survival and progeny production of the foxglove aphid, Aulacorthum solani (Kaltenbach) (Hemiptera: Aphididae), on resistant and susceptible geraniums (Pelargonium $\times$ hortorum Bailey [Geraniales: Geraniaceae]) at the highest temperature tested $\left(25.5^{\circ} \mathrm{C}\right)$, whereas there were large differences in both aphid responses between resistant and susceptible plants at the lower temperatures. All of these studies indicate that the expression of resistance was reduced or lost at higher temperatures. 
Experiments by Jackai and Inang (1992) on the legume pod borer, Maruca testulalis Geyer (Lepidoptera: Crambidae), and the brown cowpea coreid bug, Clavigralla tomentosicollis Stål (Hemiptera: Coreidae), provide inconclusive evidence for reduced resistance at high temperatures. Although the authors showed smaller differences in developmental times of the two pests between resistant and susceptible cowpeas (Vigna unguiculata (L.) Walp. [Fabales: Fabaceae]) at high temperatures $\left(30-37^{\circ} \mathrm{C}\right)$ compared to lower ones, accelerated development at high temperatures, combined with a long observation period (measured in days), opens the possibility that diminished differences in pest development between resistant and susceptible plant may not be related to a change in the expression of resistance.

\section{Reduced resistance at low temperatures.}

Eleven studies - 10 on aphids - provide ample documentation that plant resistance is reduced or lost under low temperatures. Wood and Starks (1972) showed that the fecundity of greenbugs on antibiotic sorghum and barley (Hordeum vulgare L. [Poales: Poaceae]) lines was progressively higher, and became closer to fecundity values on susceptible lines, at lower temperatures $\left(10\right.$ and $\left.15.6^{\circ} \mathrm{C}\right)$ compared to higher temperatures $\left(21.1\right.$ and $\left.26.7^{\circ} \mathrm{C}\right)$. In contrast, on susceptible lines fecundity followed a more typical temperature-dependent pattern, with larger numbers of offspring produced at higher temperatures. Schweissing and Wilde (1979) observed a smaller difference in the number of greenbugs between susceptible and resistant sorghum lines at lower temperatures $\left(21 / 10^{\circ} \mathrm{C}\right)$ compared to higher temperatures $\left(26 / 14.6\right.$ or $\left.32.2 / 21.1^{\circ} \mathrm{C}\right)$. On susceptible plants, there was a predictable decrease in greenbug numbers as temperature decreased; whereas, on resistant plants there were more greenbugs at lower temperatures than at higher temperatures. In another greenbug study, Harvey et al. (1994) showed that plant damage and death from pests on resistant and susceptible sorghum lines increased over time, and with increasing temperature. However, plant damage was delayed, and rates of death were relatively lower, on resistant plants compared to susceptible plants, but only at the lowest temperature. Findings from all three studies suggest that high temperatures maintain sorghum resistance to greenbugs while lower temperatures prevent resistance from being expressed.

Experiments with biotypes of the soybean aphid on resistant and susceptible soybean lines provide additional evidence that low 
temperatures suppress plant resistance. Richardson (2011) and Chirumamilla et al. (2014) showed that differences in aphid numbers between resistant and susceptible soybeans were smaller at the lowest temperature tested $\left(14^{\circ} \mathrm{C}\right)$ compared to higher temperatures (21 and $28^{\circ} \mathrm{C}$ ). In addition, Hough et al. (2017) reported a smaller difference in the intrinsic population growth rate of the soybean aphid between resistant and susceptible soybeans at $15^{\circ} \mathrm{C}$ compared to higher temperatures $\left(20-30^{\circ} \mathrm{C}\right)$.

An experiment with the spotted alfalfa aphid, Therioaphis maculata (Buckton) (Hemiptera: Aphididae), showed that the number of aphids recruiting to resistant alfalfa plants was similar to those found on susceptible plants at $10^{\circ} \mathrm{C}$, but not at higher temperatures (Schalk et al. 1969). Diminished resistance at low temperature occurred on some resistant lines but not others. Four other studies with the spotted alfalfa aphid (Hackerott and Harvey 1959, McMurtry 1962, Isaak et al. 1963, Kindler and Staples 1970), and one with the pea aphid (Isaak et al. 1963), were consistent in showing that the expression of resistance in alfalfa was reduced at low temperatures $\left(10-15.6^{\circ} \mathrm{C}\right)$. In all of these studies, low temperature was associated with increased fecundity and survival on resistant plants, and the differences in pest responses between resistant and susceptible plants became smaller as temperature decreased.

In the white-backed planthopper, Sogatella furcifera (Horváth) (Hemiptera: Delphacidae), Salim and Saxena (1991) reported similar rates of survival and population growth on resistant and susceptible rice (Oryza sativa L. [Poales: Poaceae]) cultivars at 12-h thermoperiods of $24 / 16$ and $26 / 18^{\circ} \mathrm{C}$, but the rates were much lower on resistant plants at $29 / 21^{\circ} \mathrm{C}$.

\section{Enhanced resistance at high and low temperatures.}

Research with the soybean aphid provides equivocal evidence that plant resistance increases at both higher and lower temperatures compared to a middle range of noninducing temperatures. Hough et al. (2017) recorded a lower rate of survival of the soybean aphid on resistant plants compared to susceptible plants at all temperatures (range $15-30^{\circ} \mathrm{C}$ ). However, whereas survival on the resistant soybean line decreased sharply between 25 and $30^{\circ} \mathrm{C}$, survival was equally high at the same two temperatures on the susceptible line. The authors concluded that high temperature induced a high level of plant resistance. Using a 
different experimental approach, but with the same resistant soybean line as that used by Hough et al. (2017), Hough (2016) found that when resistant soybeans were grown at $25^{\circ} \mathrm{C}$ and then conditioned for different periods of time at $20^{\circ} \mathrm{C}$ prior to infestation, aphid survival was progressively lower the longer plants were held at $20^{\circ} \mathrm{C}$. This could mean that a decrease in temperature caused an increase in resistance. However, without a susceptible line as a control, the results are inconclusive. Furthermore, other studies with the soybean aphid (Richardson 2011, Chirumamilla et al. 2014) found a decrease, rather than increase, in the expression of resistance at low temperature. The conflicting findings underscore the need for additional research on this crop-pest system using consistent experimental methods and a broad range of temperatures (see Recommendations for Future Research).

\section{Reduced resistance at high and low temperatures.}

Results of two studies suggest that plant resistance may decrease at both lower and higher temperatures. Salim and Saxena (1991) showed that survival and population growth of the whitebacked planthopper on resistant and susceptible rice cultivars were similar at lower (24/16 and $\left.26 / 18^{\circ} \mathrm{C}\right)$ and higher $\left(35 / 27\right.$ and $\left.36 / 28^{\circ} \mathrm{C}\right) 12$-h thermoperiods, whereas there were large differences between cultivars at an intermediate thermoperiod $\left(29 / 21^{\circ} \mathrm{C}\right)$. These results suggest that a high level of resistance was maintained only in an intermediate range of temperature. Likewise, in the greenbug, Wood and Starks (1972) found similar fecundities on resistant and susceptible sorghum and barley lines at both lower $\left(10\right.$ and $\left.15.6^{\circ} \mathrm{C}\right)$, and higher $\left(26.7\right.$ and $\left.32.2^{\circ} \mathrm{C}\right)$ temperatures, respectively, compared to intermediate temperatures (21.1 and $26.7^{\circ} \mathrm{C}$, respectively).

\section{Constant versus fluctuating temperatures.}

Kindler and Staples (1970) compared responses of the spotted alfalfa aphid on susceptible and resistant alfalfa under constant and fluctuating temperatures. Fluctuating temperatures consisted of exposing plants to a high (or low) temperature for $10 \mathrm{~h}$, then holding them at a mean temperature (average of high and low temperature) for $2 \mathrm{~h}$ before switching to the alternate low (or high) temperature. The range of constant and mean temperatures was $10-30^{\circ} \mathrm{C}$, but the authors did not specify the high and low temperatures for each mean temperature. On susceptible 
plants fecundity and survival were higher under fluctuating temperatures than at fixed temperatures. However, there were no consistent differences in aphid responses between fixed and fluctuating temperature treatments on resistant plants that would indicate a change in plant resistance. Other studies used 12-h thermoperiods (Wood and Starks 1972, Schweissing and Wilde 1979, Salim and Saxena 1991, Harvey et al. 1994) to determine if temperature had an effect on plant resistance. However, none of them included fixed temperatures as controls. Therefore, it is unclear whether alternating temperatures would have had the same effect on resistance as using constant temperatures. Additional research is needed to determine if plants respond differently to fluctuating temperatures with respect to temperature-induced resistance.

\section{Induction time and reversibility of temperature effects.}

The time required for temperature-induced changes in plant resistance may be relatively short. Chen et al. (2014) showed that conditioning wheat seedlings for $12 \mathrm{~h}$ at $14^{\circ} \mathrm{C}$ was sufficient to induce a high level of plant resistance to the Hessian fly. But very few studies have examined induction times, and those that have used treatment intervals longer than the ones in Chen et al.'s study (Sosa 1979, Hough 2016).

The amount of time required for a change in plant resistance may depend on whether temperature is causing an increase or decrease in the expression of resistance. In a study with the Hessian fly, Sosa (1979) found that temperature-induced resistance in wheat was reversible, but that the plant's response differed depending on whether it was subjected to an increase or decrease in temperature. Resistance was induced $4 \mathrm{~d}$ after seedlings were transferred from 27 to $18^{\circ} \mathrm{C}$. However, when the reciprocal transfer from 18 to $27^{\circ} \mathrm{C}$ was done, resistant plants became susceptible in just $1 \mathrm{~d}$. A possible explanation for the slower response for increased resistance may be reduced rates of biochemical changes in plants at lower temperature. Studies with the soybean aphid provide further evidence that temperature-induced changes in plant resistance are reversible when the direction of temperature change is reversed (Richardson 2011, Chirumamilla et al. 2014).

Temperature sensitivity for inducing resistance and susceptibility.

Results of a study by Chen et al. (2014) suggest that plants may differ in their sensitivity to temperatures that induce resistance compared to 
those that reverse resistance (i.e., promote susceptibility). Wheat lines that were initially susceptible to the Hessian fly at $20-22^{\circ} \mathrm{C}$ became strongly resistant with only a small decrease in temperature, whereas lines that were initially resistant at the same temperatures required a much greater increase in temperature to make them susceptible. The dissimilar responses to temperature could be a result of differences in temperature sensitivity for the molecular and biochemical processes responsible for inducing versus averting plant resistance. However, it is more likely that genetic differences in the strength of resistance among wheat lines were responsible for the differences in response to temperature (Chen et al. 2014).

Traits associated with temperature-induced changes in plant resistance.

An alteration in the expression of plant resistance associated with a change in temperature has been documented for several demographic traits in arthropods, including population growth (Schweissing and Wilde 1979, Salim and Saxena 1991, Thindwa and Teetes 1994, Richardson 2011, Chirumamilla et al. 2014, Hough et al. 2017), developmental rate or duration (Johnson et al. 1980, Thindwa and Teetes 1994), pest recruitment to plants (Schalk et al. 1969), survival (Sosa 1979, Tyler and Hatchett 1983, Salim and Saxena 1991, Walters et al. 1991, Chen et al. 2014, Hough et al. 2017), fecundity (Wood and Starks 1972, Walters et al. 1991, Harvey et al. 1994, Thindwa and Teetes 1994, Hough 2016), and adult longevity (Salim and Saxena 1991). Another trait that has been investigated but not substantiated is body weight. Jackai and Inang (1992) compared pupal body weights of the legume pod borer on resistant and susceptible cowpea plants at different temperatures, but they were unable to show a consistent pattern of differences in this response among temperatures between resistant and susceptible plants.

In addition to insect traits, some studies have used infestation or plant damage (Sosa and Foster 1976, Sosa 1979, Harvey et al. 1994, Thindwa and Teetes 1994) or plant survival (Harvey et al. 1994) as indirect evidence of temperature-induced increases or decreases in plant resistance.

\section{Experimental Approaches}

Two experimental approaches are available for evaluating the influence of temperature on the expression of plant resistance-the comparative 
approach and the plant conditioning approach. Each has advantages and limitations, which we discuss below along with guidelines for designing experiments to achieve the best results.

\section{The Comparative Approach}

The most common experimental method used to elucidate the effect of temperature on plant resistance is the comparative approach, also referred to by statisticians as 'the matched pairs design' (Toutenburg and Shalabh 2009). With this approach, pest demographic responses or plant damage are compared on resistant and susceptible plants over a range of temperatures. The relative differences in the magnitude of each response are then computed and analyzed statistically. If the differences between resistant and susceptible plants either increase or decrease at progressively higher or lower temperatures, this is considered evidence that temperature has altered the expression of resistance. An example based on percentage survival is shown in Table 2 .

An increase in the difference of a response between susceptible and resistant plants may indicate enhanced resistance, whereas a decrease suggests a weakening of resistance. A limitation of the comparative approach-especially in cases where responses between susceptible and resistant plants become more similar at high or low temperature-is that it does not ensure that differences in insect performance are not caused by direct thermal effects. For example, a decrease in the difference in pest survival between susceptible and resistant plants with increasing temperature could be interpreted as reduced plant resistance when, in fact, the cause was thermal stress. However, unless there is a simultaneous drop in survival on both resistant and susceptible plants, the

Table 2. The comparative approach for assessing temperature-induced plant resistance

\begin{tabular}{lccccc} 
Temperature $\left({ }^{\circ} \mathrm{C}\right)$ & \multicolumn{5}{c}{ Percentage pest survival } \\
\cline { 2 - 6 } & Susceptible & - & Resistant & $=$ & Difference $^{a}$ \\
\hline 15 & 85 & - & 62 & $=$ & 23 \\
20 & 90 & - & 65 & $=$ & 25 \\
25 & 92 & - & 66 & $=$ & 26 \\
30 & 80 & - & 75 & $=$ & 5 \\
\hline
\end{tabular}

$a$. The small difference in percentage survival between resistant and susceptible plants at $30^{\circ} \mathrm{C}$ compared to other temperatures suggests that resistance is not expressed at this temperature. 
differences are likely the result of a temperature-induced change in plant resistance. Plants whose resistance is based on pubescence (trichomes) may be an exception because pubescence can increase leaf temperatures (Bickford 2016). Thus, pests may develop faster on resistant plants because of an increase in temperature within the leaf boundary layer.

Accelerated temperature-dependent development at high temperatures, or a reduction in development at low temperatures due to limited heat energy, also may obscure effects of resistance on growth and development. In such cases, it may be difficult to distinguish between direct and indirect temperature effects. A solution to this problem is to obtain demographic data for multiple life history traits and then compute intrinsic rates of population growth for resistant and susceptible plants (see Recommendations for Future Research).

\section{The Plant Conditioning Approach}

With this approach, resistant plants are propagated at a neutral temperature (i.e., one known or presumed to have no effect on resistance) and then transferred to experimental temperatures for different periods of time (Chen et al. 2014, Hough 2016). Experimental temperatures should include those known to induce resistance as well as neutral temperatures which serve as controls. If unknown, temperatures that span the higher and lower ranges should be selected because they are most likely to induce a change in resistance. Subsequently, plants are infested with an equal number of pests, and demographic data are collected until all pests have died. Data are analyzed for the effects of temperature, conditioning time, and the two-way interaction. An example based on percentage survival is shown in Table 3.

Table 3. The plant conditioning approach for assessing temperature- induced plant resistance Temperature $\left({ }^{\circ} \mathrm{C}\right)$

Percentage pest survival ${ }^{a}$

\begin{tabular}{lccc}
\cline { 2 - 4 } & & Conditioning time (d) & \\
\cline { 2 - 4 } & 0 & 3 & 6 \\
\hline 20 & 50 & 25 & 10 \\
30 & 15 & 15 & 15 \\
\hline
\end{tabular}

a. The uniformly low survival at $30^{\circ} \mathrm{C}$ compared to $20^{\circ} \mathrm{C}$ with no conditioning ( $0 \mathrm{~d}$ ) indicates direct thermal stress at the higher temperature. In contrast, the reduction in survival at $20^{\circ} \mathrm{C}$ when plants are conditioned at that temperature, and the effect of longer conditioning, suggests that low temperature has increased the expression of resistance. 
An assumption of the plant conditioning approach is that resistance will increase (or decrease) the longer that plants are exposed to inducing temperatures. Thus, this approach has the unique advantage of revealing whether the strength of resistance increases or decreases as a function of plant exposure time. Also, because plants are conditioned for different periods of time before infestation, differences in pest responses among conditioning times are likely to be a result of temperature-induced changes in resistance rather than direct temperature effects. However, a limitation of conditioning only resistant plants is that it does not provide a control for potential direct temperature effects on pests. The inclusion of susceptible plants in the experimental design blends both the plant conditioning and comparative approaches, and should be done wherever possible.

\section{Recommendations for Future Research}

Our understanding of how temperature impacts plant resistance to arthropod pests is somewhat limited by the number of studies conducted to date, the taxonomic scope of crops and pests investigated, and in a few cases deficiencies in design, analysis, or data collected. Experiments that cover a broader range of plants and insects, and address questions about temperature-plant interactions that have received limited attention, are needed to provide a more complete understanding of how temperature influences plant resistance. The following sections offer recommendations for future research in several key areas.

\section{Range of Temperatures Tested}

Experimental designs should include a broad, but ecologically relevant, range of temperatures that plants and arthropods experience under typical growing conditions in the crop environment. To guide the selection of appropriate temperatures, preliminary experiments should be done to establish the upper and lower threshold temperatures for pest development, as well as temperatures that cause direct stress to pests.

Of the four ways that temperature has been shown to affect plant resistance (high or low temperature associated with an increase or decrease in resistance), the most problematic for distinguishing direct from indirect effects are situations where high or low temperatures appear 
to reduce the level of resistance. This is particularly so when using the comparative approach because convergence of pest developmental rates, survival, fecundity, and/or population growth among resistant and susceptible plants at progressively higher or lower temperatures might be interpreted as a loss of resistance when, in fact, they are a result of direct temperature effects. For example, a review of the data from Jackai and Inang (1992) for the legume pod borer and the brown cowpea coreid bug showed that development on resistant and susceptible plants became shorter, and closer to each other, as temperature increased, suggesting the possibility of weakened resistance. But without additional information, it is not possible to determine whether resistance had become weaker, or if accelerated development had obscured differences in development times. The opposite problem can occur at low temperatures. Pest developmental rates may be equally slow on resistant and susceptible plants, not because of weakened plant resistance, but because there is insufficient heat energy for development.

Once high and low temperatures have been selected, several intermediate temperatures should be included. If temperature-induced changes in resistance occur, investigators should determine whether they follow a linear pattern, with resistance increasing (or decreasing) at progressively higher or lower temperatures, or if the relationship is quadratic, with resistance becoming stronger, then weaker (or vice versa), as temperatures increase or decrease. For example, experiments with the soybean aphid suggest that a change in the expression of resistance may occur more than once over a wide range of temperatures (Hough 2016, Hough et al. 2017).

\section{Response to Fixed Versus Fluctuating Temperatures}

Of the studies that have demonstrated a temperature effect on plant resistance, several involved exposing the same plants to a change in temperature (Wood and Starks 1972, Schweissing and Wilde 1979, Sosa 1979, Salim and Saxena 1991, Harvey et al. 1994, Chen et al. 2014, Hough 2016). However, because none of the studies used fixed temperatures as controls, it is unclear whether switching temperatures would have had the same effect on resistance as using constant temperatures. For example, Harvey et al. (1994) compared greenbug resistance on resistant and susceptible sorghum plants at low $\left(20^{\circ} \mathrm{C}\right)$ and high $\left(28^{\circ} \mathrm{C}\right)$ constant 
temperatures as well as a 12 -h thermoperiod $\left(20 / 28^{\circ} \mathrm{C}\right)$. Our analysis of their data indicated that changes in the strength of resistance were inversely related to temperature, and that an intermediate level of resistance occurred in the thermoperiod treatment where the average temperature was between the low and high fixed temperatures. However, it was not possible to determine if temperature-induced changes in plant resistance differed under fluctuating versus constant temperatures. To do so, thermoperiods would need to have been selected so that the average temperature for the thermoperiod was the same as the low and high fixed temperatures $\left(30 / 26^{\circ} \mathrm{C}\right.$ for the $28^{\circ} \mathrm{C}$ high; $22 / 18^{\circ} \mathrm{C}$ for the $20^{\circ} \mathrm{C}$ low). Experiments with adequate controls are especially important in cases where temperatures cross the threshold for inducing plant responses. Experiments should also include treatments where the magnitude of temperature change crossing the response threshold varies. For example, if tests show that the critical temperature for inducing a change in resistance is $24^{\circ} \mathrm{C}$, treatments might include $26 / 22,28 / 20$, and $30 / 18^{\circ} \mathrm{C}$ with a constant $24^{\circ} \mathrm{C}$ as a control. With better-designed experiments, predictions about temperature effects on resistance could be improved under the dynamically changing temperature conditions that prevail in crop environments.

\section{Induction Time}

The time required for temperature to induce changes in plant resistance appears to be short. Chen et al. (2014) measured a change in resistance to the Hessian fly by exposing wheat seedlings for $12 \mathrm{~h}$ to inducing temperatures. However, because only a few studies have considered the question of exposure time (Sosa 1979, Chen et al. 2014, Hough 2016), and all of them used longer times than Chen et al., it is possible that exposure times as short as an hour or less may be sufficient to induce a change in plant resistance. Experiments that test shorter exposure times are needed.

\section{Temperature Sensitivity for Inducing Resistance and Susceptibility}

A study by Chen et al. (2014) suggests that plant sensitivity to temperatures that induce versus diminish resistance may not be the same. Their results showed that wheat lines that were initially susceptible to 
the Hessian fly at $20-22^{\circ} \mathrm{C}$ acquired strong resistance with only a small decrease in temperature, whereas lines that were initially resistant in the same temperature range required a larger increase in temperature for resistance to be lost. The apparent asymmetry in plant sensitivity to temperature in Chen et al.'s study needs further investigation because there were genetic differences among wheat lines for the range of temperature that induced resistance. The fact that some plants were initially susceptible while others were resistant could have biased the results. Therefore, future experiments should use the same genetic lines to determine if plant sensitivity to temperatures that induce versus reduce resistance are different.

\section{Reversibility of Temperature Effects}

A few studies have shown that reversing the direction of temperature change will reverse the effect temperature has on plant resistance (Sosa 1979, Richardson 2011, Chen et al. 2014, Chirumamilla et al. 2014). However, these studies concerned only two pests-Hessian fly and soybean aphid. Additional experiments that include reciprocal changes in temperature are needed for a broader spectrum of crop pests. This kind of information is especially relevant under field conditions where temperature fluctuations are common. For example, if an increase in field temperature increases the expression of resistance, whereas a decrease in temperature reduces the level of resistance, knowing the length of time a plant is exposed to ascending or descending temperatures that cross the response threshold may improve predictions about the impact of plant resistance on pest populations.

\section{Traits Used to Measure Resistance}

Of the 26 studies we reviewed, 12 (46\%) assessed temperature-induced effects on plant resistance for only a single pest trait or plant response, while six studies (23\%) evaluated just two traits. Multiple traits and/or plant responses were tested in eight studies (31\%). Experiments based on a small number of traits are limited in their ability to demonstrate if and how temperature impacts plant resistance. For example, if an experiment used only one or two traits and showed no temperature-induced plant effect, it is still possible that other traits may have revealed 
a temperature-induced change in the expression of resistance. Indeed, of the studies we reviewed that evaluated multiple traits, in most cases a significant change in resistance was observed for only some of the traits.

Because some pest life history traits (e.g., development time, fecundity, survival) may respond differently and in opposite directions to changes in plant resistance, another limitation of restricting experiments to one or only a few traits is that it does not allow the investigator to determine the overall net effect of temperature on plant resistance and, thus, pest population growth. In fact, even statistically nonsignificant trends in responses, when combined with significant responses, may have a cumulative effect on population growth (Hough et al. 2017). A strategy used by Hough (2016) and Hough et al. (2017) was to investigate the effect of temperature on the full range of pest life history traits, and then to compute life table statistics which integrated across demographic variation in fecundity, development, and survival. The advantage of using this synthetic approach to compare responses on resistant and susceptible plants is that it shows the net effect of temperature on pest population growth, including direct effects. However, evaluating individual life history traits is also important because it documents which traits are influenced by a change in resistance.

\section{Physiological and Genomic Investigations}

The physiological and molecular mechanisms underlying temperatureinduced shifts in plant resistance are not well-understood. Temperature has been shown to affect the production of both primary and secondary metabolites (Pisek et al. 1973, Salim and Saxena 1991, Basra 2001, Zvereva and Kozlov 2006, DeLucia et al. 2012, Jamieson et al. 2017, Vaughan et al. 2018, Pinto and Ongaratto 2019). However, establishing causal links between temperature, secondary chemistry, and plant resistance to insects is difficult (Vaughan et al. 2018). For example, Veteli et al. (2002) showed that elevated temperatures were correlated with a $25 \%$ reduction in phenolics, and a $23 \%$ decrease in all secondary metabolites, in the dark-leaved willow, Salix myrsinifolia (Salisb.) (Malpighiales: Salicaceae). They also showed that elevated temperatures were associated with increased larval growth of the leaf beetle, Phratora vitellinae (L.) (Coleoptera: Chrysomelidae). But while it is possible that the faster growth rate of beetles was caused by the lower concentration of 
secondary chemicals, it is more likely that development was directly influenced by the higher temperature. Alternatively, a change in plant nutritional quality could have influenced insect development (Pinto and Ongaratto 2019).

Although the molecular basis for temperature effects on plant resistance is still uncertain, temperature has been shown to influence the production of intermediary chemicals such as jasmonic acid and salicylic acid, both of which are a part of the signaling pathways for producing secondary metabolites used by plants for defense (DeLucia et al. 2012, Vaughan et al. 2018). However, currently there is no published information about how temperature affects gene expression affecting plant resistance. Future studies at the molecular and genomic levels may enable researchers to manipulate plants to enhance resistance at temperatures that fall within the range of crop production.

\section{Climate Change}

Recent studies concerning temperature effects on plant chemistry, and how this impacts insects, have focused on effects of global climate change (Zvereva and Kozlov 2006, Vaughan et al. 2018, Pinto and Ongaratto 2019. Because climate change typically involves more than one physical factor, effects of climate change on plants and insects are expected to be complex (DeLucia et al. 2012, Pinto and Ongaratto 2019). For example, Veteli et al. (2002) used a controlled environment in which he compared the effects of elevated temperature and $\mathrm{CO} 2$, singly and together, on responses of dark-leaved willow and the leaf beetle $P$. vitellinae. Increased levels of each physical factor resulted in lower concentrations of plant phenolics. However, whereas elevated temperature caused an increased growth rate of beetles, elevated $\mathrm{CO} 2 \mathrm{had}$ the opposite effect. In addition, nitrogen and water were lower in leaves under elevated $\mathrm{CO} 2$. However, an increase in temperature had no effect on either nitrogen or water. These findings indicate that the effect of temperature on plant resistance in areas experiencing climate change should be evaluated in the context of other environmental changes. Experiments that use a factorial treatment structure will allow researchers to test for effects of temperature individually, and in combination with other climate factors. 


\section{Variation Among Insect and Plant Taxa}

Experiments conducted to date encompass a relatively narrow taxonomic scope, with aphids and grain crops representing the dominant taxa. Studies with a broader range of pests and crop plants are needed to determine if the effects of temperature on plant resistance are specific to certain taxonomic groups, or if there is a high degree of variation within closely related taxa.

Insect biotypes exhibit genetic variation that is linked to plant resistance. Therefore, it is reasonable to assume that different biotypes will respond differently to temperature-induced effects on plant resistance. Our review of biotypes for two pest species - the greenbug (Wood and Starks 1972, Thindwa and Teetes 1994) and the Hessian fly (Sosa and Foster 1976, Tyler and Hatchett 1983, Chen et al. 2014)—showed that temperature had a similar effect on plant resistance with respect to the direction of temperature change (higher or lower) and the expression of resistance. However, differences were observed among biotypes of both species in the range of temperatures that induced effects on resistance and in the magnitude of the change in responses at a given temperature. From this we conclude that experiments should be repeated as new biotypes evolve.

\section{Plant Age and Stage Sensitivity}

To date, the question of whether temperature-induced plant resistance varies with the age or stage of plant development has not been addressed. However, there is ample evidence that plant resistance is not uniform throughout plant development (Painter 1951, Smith 2006). Therefore, it is reasonable to expect that temperature effects on resistance also vary with the age/stage of the crop plant. Thus, tests to determine temperature effects on plant resistance to insect pests should be conducted at different stages of plant development.

\section{Experimental Approaches}

The comparative approach has the key advantage of measuring relative differences in responses between resistant and susceptible plants across a range of temperatures. Susceptible plants serve as a control, 
which helps to determine whether temperature is having a direct effect on pests or an indirect effect by modifying the expression of plant resistance. Therefore, all experiments should use this approach. In contrast, the plant conditioning approach is designed to reveal changes in the strength of resistance based on the length of time a plant is exposed to inducing temperatures. As such, it offers a second way to determine whether a given temperature influences the expression of resistance. However, some plants may not respond to different exposure times. In addition, unlike the comparative approach, tests on only resistant plants do not provide a control for direct temperature effects. Therefore, we recommend that researchers use the comparative approach initially. In cases where temperature is shown to have an effect on resistance, additional experiments using the plant conditioning approach could be done to evaluate changes in the strength of resistance. Alternatively, both approaches could be combined in a single experiment.

\section{Conclusion}

A more comprehensive understanding of the interactive effects of temperature on trophic interactions between herbivorous insects and crop plants is important for deploying future plant resistance programs, and for maintaining the economic sustainability of agricultural production. Well-designed experiments will help to achieve that goal. Developing cultivars that have greater resistance over a broader range of temperatures will help to minimize the use of insecticides, reduce losses to pest damage, and increase economic benefits to producers. Understanding the effects of temperature on plants and pests will also be important for predicting the potential effects of climate change on agricultural production.

Acknowledgments We thank Drs. Therese Poland, Melody Keena, and E. Alan Cameron for editorial assistance. We also thank anonymous reviewers for suggestions.

\section{References}

Basra, A. S. (ed.). 2001. Crop responses and adaptations to temperature stress. The Haworth Press, New York, NY. 
Beck, S. D. 1965. Resistance of plants to insects. Annu. Rev. Entomol. 10: 207-232.

Bickford, C. P. 2016. Ecophysiology of leaf trichomes. Funct. Plant Biol. 43: 807-814.

Cartwright, W. B., R. M. Caldwell, and L. E. Compton. 1946. Relation of temperature to the expression of resistance in wheats to Hessian fly. J. Am. Soc. Agron. 38: 259-263.

Casteel, C. L., C. M. Ranger, E. A. Backus, M. R. Ellersieck, and D. W. Johnson. 2006. Influence of plant ontogeny and abiotic factors on resistance of glandularhaired alfalfa to potato leafhopper (Hemiptera: Cicadellidae). J. Econ. Entomol. 99: 537-543.

Chen, M. S., S. Wheeler, H. Wang, and R. J. Whitworth. 2014. Impact of temperatures on Hessian fly (Diptera: Cecidomyiidae) resistance in selected wheat cultivars (Poales: Poaceae) in the Great Plains region. J. Econ. Entomol. 107: 1266-1273.

Chirumamilla, A., C. B. Hill, and G. L. Hartman. 2014. Stability of soybean aphid resistance in soybean across different temperatures. Crop Sci. 54: 2557-2563.

Dahms, R. G., and R. H. Painter. 1940. Rate of reproduction of the pea aphid on different alfalfa plants. J. Econ. Entomol. 33: 482-485.

DeLucia, E. H., P. D. Nabity, J. A. Zavala, and M. R. Berenbaum. 2012. Climate change: resetting plant-insect interactions. Plant Physiol. 160: 1677-1685.

Denno, J., and M. S. McClure. 1983. Variable plants and herbivores in natural and managed systems. Academic Press, New York, NY.

Hackerott, H. L., and T. L. Harvey. 1959. Effect of temperature on spotted alfalfa aphid reaction to resistance in alfalfa. J. Econ. Entomol. 52: 949-953.

Harvey, T. L., G. E. Wilde, K. D. Kofoid, and P. J. Bramel-Cox. 1994. Temperature effects on resistance to greenbug (Homoptera: Aphididae) biotype I in sorghum. J. Econ. Entomol. 87: 501-503.

Hough, A. 2016. The indirect and direct effects of temperature and host plant resistance on population growth of soybean aphid (Aphis glycines) biotype 1. M.S. thesis, Kansas State University, Manhattan, KS.

Hough, A. R., J. R. Nechols, B. P. McCornack, D. C. Margolies, B. K. Sandercock, D. Yan, and L. Murray. 2017. The effect of temperature and host plant resistance on population growth of the soybean aphid biotype 1 (Hemiptera: Aphididae). Environ. Entomol. 46: 58-67.

Isaak, A., E. L. Sorensen, and E. E. Ortman. 1963. Influence of temperature and humidity on resistance in alfalfa to the spotted alfalfa aphid and pea aphid. J. Econ. Entomol. 56: 53-57.

Ishaaya, I. 1986. Nutritional and allelochemic insect-plant interactions relating to digestion and food intake: some examples, Chap. 7, pp. 192-223. In J. R. Miller and T. A. Miller (eds.), Insect-plant interactions. Springer-Verlag, New York, NY.

Jackai, L. E. N., and E. E. Inang. 1992. Developmental profiles of two cowpea pests on resistant and susceptible Vigna genotypes under constant temperatures. J. Appl. Entomol. 113: 217-227. 
Jamieson, M. A., L. A. Burkle, J. S. Manson, J. B. Runyon, A. M. Trowbridge, and J. Zientek. 2017. Global change effects on plant-insect interactions: the role of phytochemistry. Curr. Opin. Insect Sci. 23: 70-80.

Johnson, K. J. R., E. L. Sorensen, and E. K. Horber. 1980. Effect of temperature and glandular-haired Medicago species on development of alfalfa weevil larvae. Crop Sci. 20: 631-633.

Kindler, S. D., and R. Staples. 1970. The influence of fluctuating and constant temperatures, photoperiod, and soil moisture on the resistance of a

Koch, K., G. K. Chapman, J. Louis, T. Heng-Moss, and G. Sarath. 2016. Plant tolerance: a unique approach to control Hemipteran pests. Front Plant Sci. 7: 1363.

McMurtry, J. A. 1962. Resistance of alfalfa to spotted alfalfa aphid in relation to environmental factors. Hilgardia. 32: 501-539.

Painter, R. 1951. Insect resistance in crop plants. Macmillan, New York, NY.

Pinto, C. P., and S. Ongaratto. 2019. Influence of abiotic factors on the resistance of plants to insects. EntomoBrasilis. 12: 1-5.

Pisek, A., W. Larcher, A. Vegis, and K. Napp-Zinn. 1973. Effect of temperature on metabolic processes, pp. 102-144. In H. Precht, J. Christophersen, H. Hensel, and W. Larcher (eds.), Temperature and life. Springer-Verlag, Berlin, Germany.

Precht, H., J. Christophersen, H. Hensel, and W. Larcher. 1973a. Temperature and life. Springer-Verlag, Berlin, Germany.

Precht, H., H. Laudien, and B. Havsteen. 1973b. The normal temperature range, pp. 302-318. In H. Precht, J. Christophersen, H. Hensel, and W. Larcher (eds.), Temperature and life. Springer-Verlag, Berlin, Germany.

Randolph, T. L., S. C. Merrill, and F. B. Peairs. 2008. Reproductive rates of Russian wheat aphid (Hemiptera: Aphididae) biotypes 1 and 2 on a susceptible and a resistant wheat at three temperature regimes. J. Econ. Entomol. 101: 955-958.

Richardson, M. L. 2011. Temperature influences the expression of resistance of soybean (Glycine max) to the soybean aphid (Aphis glycines). J. Appl. Entomol. 136: 641-645.

Salim, M., and R. C. Saxena. 1991. Temperature stress and varietal resistance in rice effects on whitebacked planthopper. Crop Sci. 31: 1620-1625.

Schalk, J. M., S. D. Kindler, and G. R. Manglitz. 1969. Temperature and preference of the spotted alfalfa aphid for resistant and susceptible alfalfa plants. J. Econ. Entomol. 62: 1000-1003.

Schweissing, F. C., and G. Wilde. 1979. Temperature and plant nutrient effects on resistance of seedling sorghum to the greenbug. J. Econ. Entomol. 72: 20-23.

Shuman, M. C., and I. T. Baldwin. 2016. The layers of plant responses to insect herbivores. Annu. Rev. Entomol. 61: 373-394.

Smith, C. M. 2006. Plant resistance to arthropods. Springer, Dordrecht, The Netherlands.

Sosa, 0., Jr. 1979. Hessian fly: resistance of wheat as affected by temperature and duration of exposure. Environ. Entomol. 8: 280-281. 
Sosa, O., Jr., and J. E. Foster. 1976. Temperature and expression of resistance in wheat to the Hessian fly. Environ. Entomol. 5: 333-336.

Thindwa, H. P., and G. L. Teetes. 1994. Effect of temperature and photoperiod on sorghum resistance to biotype $\mathrm{C}$ and E greenbug (Homoptera: Aphididae). J. Econ. Entomol. 87: 1366-1372.

Tingey, W. M., and S. R. Singh. 1980. Environmental factors influencing the magnitude and expression of resistance, Chap. 5, pp. 89-113. In F. G. Maxwell and P. R. Jennings (eds.), Breeding plants resistant to insects. Wiley, New York, NY.

Toutenburg, H., and S. Shalabh. 2009. Statistical analysis of designed experiments, 3rd ed. Springer-Verlag, New York, NY.

Tyler, J. M., and J. H. Hatchett. 1983. Temperature influence on expression of resistance to Hessian fly (Diptera: Cecidomyiidae) in wheat derived from Triticum tauschii. J. Econ. Entomol. 76: 323-326.

Vaughan, M. M., A. Block, S. A. Christenen, L. H. Allen, and E. A. Schmelz. 2018. The effects of climate change associated abiotic stresses on maize phytochemical defenses. Phytochem. Rev. 17: 37-49.

Vegis, A. 1973. Effect of temperature on growth and development, pp. 145-169. In H. Precht, J. Christophersen, H. Hensel, and W. Larcher (eds.), Temperature and life. Springer-Verlag, Berlin, Germany.

Veteli, T. O., K. Kuokkanen, R. Julkunen-Titto, H. Roininen, and J. Tahvanainen. 2002. Effects of elevated $\mathrm{CO} 2$ and temperature on plant growth and herbivore defensive chemistry. Glob. Change Biol. 8: 1240-1252.

Walters, D. S., J. Harmon, R. Craig, and R. O. Mumma. 1991. Effect of temperature on glandular trichome exudate composition and pest resistance in geranium. Entomol. Exp. Appl. 60: 61-69.

Went, F. W. 1953. The effect of temperature on plant growth. Annu. Rev. Plant Physiol. 4: 347-362.

Wood, E., and K. Starks. 1972. Effect of temperature and host plant interaction on the biology of three biotypes of the greenbug. Environ. Entomol. 1: 230-234.

Zhu-Salzman, K., D. S. Luthe, and G. W. Felton. 2008. Arthropod-inducible proteins: broad spectrum defenses against multiple herbivores. Plant Physiol. 146: 852-858.

Zvereva, E. L., and M. V. Kozlov. 2006. Consequences of simultaneous elevation of carbon dioxide and temperature for plant-herbivore interactions: a metaanalysis. Glob. Change Biol. 12: 27-41. 